\title{
Erratum to: Sustainable smallholder poultry interventions to promote food security and social, agricultural, and ecological resilience in the Luangwa Valley, Zambia
}

\author{
Sarah E. Dumas ${ }^{1,2} \cdot$ Luke Lungu $^{3}$ - Nathan Mulambya ${ }^{3}$ - Whiteson Daka ${ }^{3}$. \\ Erin McDonald ${ }^{1} \cdot$ Emily Steubing $^{1} \cdot$ Tamika Lewis $^{1} \cdot$ Katherine Backel $^{1} \cdot$ Jarra Jange $^{4}$ • \\ Benjamin Lucio-Martinez ${ }^{4}$ - Dale Lewis ${ }^{3}$ • Alexander J. Travis ${ }^{1,2}$
}

Published online: 20 June 2016

(C) Springer Science+Business Media Dordrecht and International Society for Plant Pathology 2016

\section{Erratum to: Food Security}

DOI 10.1007/s12571-016-0579-5

A file conversion error resulted in one box in Figure 4 to read "expectancy" when it should read "short life expectancy. Figure 4 has been corrected as below, in all published copies of the article.

Alexander J. Travis

ajt32@cornell.edu

1 Baker Institute for Animal Health, Cornell University,

Ithaca, NY 14853, USA

2 Atkinson Center for a Sustainable Future, Cornell University, Ithaca, NY 14853, USA

3 Community Markets for Conservation (COMACO), Wildlife Conservation Society, Manda Hills, Lusaka, Zambia

4 Department of Population Medicine and Diagnostic Sciences, Cornell University, Ithaca, NY 14853, USA 
Fig. 4 Mechanisms by which poverty and low ASF

consumption lead to reductions in human health and economic development, having negative impacts on $\mathrm{HH}$ and regional resilience

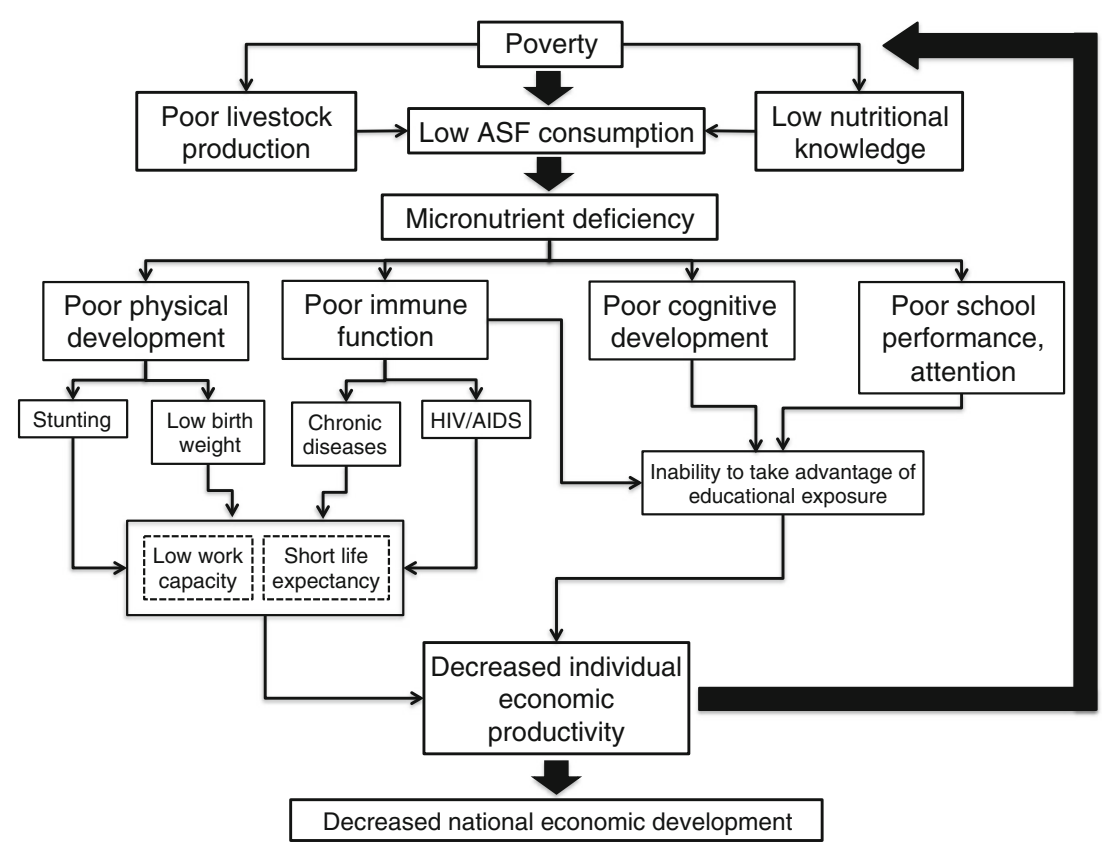

